\title{
Inconsistencies in Guidelines for Visual Health Surveillance of VDT Workers
}

\author{
María del Mar Seguí ${ }^{1}$, Elena RondA ${ }^{2}$ and Peter Wimpenny ${ }^{3}$
}

${ }^{1}$ Optic, Pharmacology and Anatomy Department, Public Health Research Group, University of Alicante, ${ }^{2}$ Public Health Department, Public Health Research Group, Occupational Health Research Centre (CISAL), CIBER Epidemiology and Public Health (CIBERESP), University of Alicante, Spain and ${ }^{3}$ Joanna Briggs Collaborating Centre, The Robert Gordon University (RGU), UK

\begin{abstract}
Inconsistencies in Guidelines for Visual Health Surveillance of VDT Workers: María del Mar Seguí, et al. Optic, Pharmacology and Anatomy Department, Public Health Research Group, University of Alicante, Spain-Objectives: In Europe, 25\% of workers use video display terminals (VDTs). Occupational health surveillance has been considered a key element in the protection of these workers. Nevertheless, it is unclear if guidelines available for this purpose, based on EU standards and available evidence, meet currently accepted quality criteria. The aim of this study was to appraise three sets of European VDT guidelines (UK, France, Spain) in which regulatory and evidencebased approaches for visual health have been formulated and recommendations for practice made. Methods: Three independent appraisers used an adapted AGREE instrument with seven domains to appraise the guidelines. A modified nominal group technique approach was used in two consecutive phases: first, individual evaluation of the three guidelines simultaneously, and second, a face-to-face meeting of appraisers to discuss scoring. Analysis of ratings obtained in each domain and variability among appraisers was undertaken (correlation and kappa coefficients). Results: All guidelines had low domain scores. The domain evaluated most highly was Scope and purpose, while Applicability was scored minimally. The UK guidelines had the highest overall score, and the Spanish ones had the lowest. The analysis of reliability and differences between scores in each domain showed a high level of agreement. Conclusions: These results suggest current guidelines used in these countries need an update. The formulation of evidence-base European guidelines on VDT could help to reduce the significant
\end{abstract}

Received Sep 2, 2011; Accepted Oct 17, 2011

Published online in J-STAGE Dec 10, 2011

Correspondence to: M. del M. Seguí, Departamento de Óptica, Farmacología y Anatomía, Universidad de Alicante, Carretera San Vicente del Raspeig s/n, 03690 San Vicente del Raspeig, Alicante, España (e-mail:mm.segui@ua.es) variation of national guidelines, which may have an impact on practical application.

(J Occup Health 2012; 54: 16-24)

Key words: Computer terminals, Occupational diseases, Occupational exposure, Occupational health, Population surveillance

The expansion of information technologies in recent decades has resulted in increased use of video display terminals (VDTs) in the workplace. In Europe, about $26 \%$ of workers use computers during their workday ${ }^{1)}$, whereas in 1990 , the rate was $13 \%{ }^{2}$.

Tasks that involve sitting in front of a computer screen have been related with ocular and visual disturbances such as visual fatigue ${ }^{3,4)}$. Several studies reveal that these complaints are one of the most frequent health problems among VDT workers ${ }^{5-8)}$. Furthermore, with today's extensive computer use, the numbers of sufferers is significant, and despite limited evidence of certificated sickness, there is potential for this to contribute to work-related ill health, particularly in conjunction with stress, anxiety and depression, and result in increased ill health and lost working days $^{9)}$.

Visual health surveillance has been considered a key element for the protection of workers using VDTs $^{10)}$. Consequently, different guidelines have been developed in Europe. These recommendations would be expected to be similar, since they draw on a limited range of international literature and are all derived from the same European directive ${ }^{11)}$. Hence, it might be considered they would be similar in nature, although it is acknowledged that even if the same topic is covered, differences might exist in the questions asked, style of presentation, cultural factors and criteria for recommendations.

However, it is not clear whether current guide- 
lines meet accepted quality criteria and if there is some degree of comparability within the European context. To our knowledge, previous studies have not compared and evaluated guidelines used in Europe for visual health surveillance, although this has happened with other health problems such as psoriasis ${ }^{12)}$, pressure ulcers ${ }^{13)}$ or diabetes ${ }^{14)}$. Therefore, a review seems timely. Accordingly, this paper reports on the appraisal and comparison of guidelines used in three European countries for health surveillance of VDT workers.

\section{Materials and Methods}

\section{General design}

Two consecutive phases were undertaken: firstly, individual evaluation of the three guidelines simultaneously, and secondly, a face-to-face meeting of appraisers (Fig. 1).

We selected a convenient sample of available national guidelines currently in force in Europe that have been approved by institutions responsible for workers' safety and health and used for health surveillance of VDT workers. These consisted of guidelines from the United Kingdom $(\mathrm{UK})^{15)}$, France $^{16)}$ and Spain $^{17)}$ (Table 1).

Guideline appraisal was carried out by three independent appraisers: two Spanish and one British, all of whom are professionals in disciplines related to the subject. All appraisers could speak English and Spanish. The French guidelines were translated into English.

\section{Instrument}

The evaluation tool was adapted from the AGREE instrument ${ }^{18)}$. It was adapted to appraise guidelines from the perspective of visual health based on a focus group discussion involving nine experts in occupational and visual health with a good internal consistency (Cronbach's alpha $>0.60)^{19}$.

The appraisal instrument consisted of 18 items, 12 of which are grouped into five domains (Table 2). The first domain, Scope and purpose, analyzed whether the visual health objectives were sufficiently well defined and if the target population was clearly described. The second domain, Stakeholder involve-

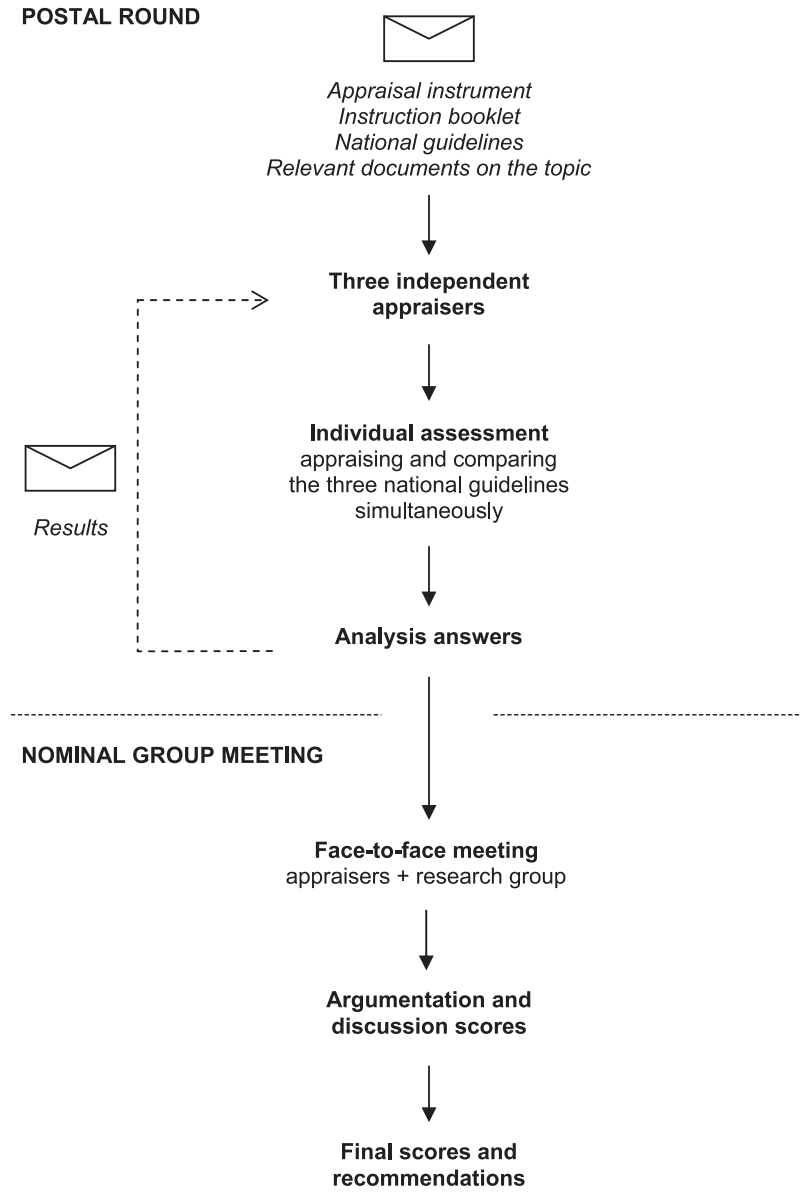

Fig. 1. UK, French and Spanish VDT guidelines: quality appraisal approach.

ment, reviewed the profile of the professionals who participated in developing the guidelines, whether they consulted the needs of the exposed workers and if a pilot study on guideline performance was made prior to their publication. The third domain, Rigor of development, assessed whether the contents are based on available and recently updated scientific evidence. The fourth domain, Clarity and presentation, evaluated the clarity of language and format of the recommendations. The fifth domain, Applicability, addressed the cost implications of implementation. Two additional domains were included ${ }^{13)}$ : Contribution, which was

Table 1. Guidelines included in the appraisal

\begin{tabular}{lllcc}
\hline Country & Title & Editor & Last review & Reference \\
\hline United Kingdom & Work with display screen equipment & Health and Safety Executive (HSE) & 2003 & 15 \\
France & Écrans de visualisation. Santé et ergonomie & $\begin{array}{l}\text { Institut National de Recherche et } \\
\text { de Securité (INRS) }\end{array}$ & 2005 & 16 \\
Spain & Protocolos de Vigilancia Sanitaria Específica. & $\begin{array}{l}\text { Ministerio de Sanidad y Consumo } \\
\text { (MSC) }\end{array}$ & 1999 & 17 \\
& Pantallas de visualización de datos & & \\
\hline
\end{tabular}


Table 2. Overview of median item scores and standardized domain scores by three appraisers

\begin{tabular}{|c|c|c|c|}
\hline Domain/item & $\begin{array}{c}\text { UK } \\
\text { guidelines }\end{array}$ & $\begin{array}{c}\text { French } \\
\text { guidelines }\end{array}$ & $\begin{array}{c}\text { Spanish } \\
\text { guidelines }\end{array}$ \\
\hline \multicolumn{4}{|l|}{ Scope and purpose } \\
\hline $\begin{array}{l}1 \text { The specific objectives of the guidelines aimed at preventing ocular or visual disturbances associated } \\
\text { with exposure are specifically described }\end{array}$ & 4 & 3 & 3 \\
\hline $\begin{array}{l}2 \text { The visual requirements of exposed workers to whom the guidelines are meant to apply are specifi- } \\
\text { cally described }\end{array}$ & 4 & 3 & 3 \\
\hline Standardized domain score of scope and purpose & $100 \%$ & $67 \%$ & $56 \%$ \\
\hline \multicolumn{4}{|l|}{ Stakeholder involvement } \\
\hline $\begin{array}{l}3 \text { The guideline development groups include ocular and visual health specialists together with special- } \\
\text { ists in occupational health }\end{array}$ & 2 & 2 & 1 \\
\hline $\begin{array}{l}4 \text { The individuals within professional sectors most vulnerable to visual disturbances' views and prefer- } \\
\text { ences have been consulted }\end{array}$ & 1 & 1 & 1 \\
\hline 5 The guidelines have been piloted among exposed workers & 1 & 1 & 1 \\
\hline Standardized domain score of stakeholder involvement & $11 \%$ & $7 \%$ & $7 \%$ \\
\hline \multicolumn{4}{|l|}{ Rigor of development } \\
\hline $\begin{array}{l}6 \text { Systematic methods were used to search for evidence related to ocular and visual disturbances associ- } \\
\text { ated with exposure }\end{array}$ & 1 & 1 & 1 \\
\hline $\begin{array}{l}7 \text { The criteria for selecting the evidence related to the visual system are clearly defined within the } \\
\text { guidelines }\end{array}$ & 1 & 1 & 1 \\
\hline 8 The recommendations for surveillance in regards to visual health are evidence-based and referenced & 3 & 1 & 1 \\
\hline 9 A procedure for updating visual health surveillance contents is provided & 1 & 1 & 1 \\
\hline Standardized domain score of rigor of development & $19 \%$ & $6 \%$ & $3 \%$ \\
\hline \multicolumn{4}{|l|}{ Clarity and presentation } \\
\hline 10 The steps to carry out the visual health surveillance are clearly presented & 3 & 2 & 2 \\
\hline 11 All areas of ocular and visual health for health surveillance are easily identifiable & 2 & 3 & 2 \\
\hline Standardized domain score of clarity and presentation & $50 \%$ & $56 \%$ & $22 \%$ \\
\hline \multicolumn{4}{|l|}{ Applicability } \\
\hline 12 The general potential cost implications of applying the guidelines have been considered & 1 & 1 & 1 \\
\hline Standardized domain score of applicability & $0 \%$ & $0 \%$ & $0 \%$ \\
\hline \multicolumn{4}{|l|}{ Contribution $^{\mathrm{a}}$} \\
\hline $\begin{array}{l}13 \text { The guidelines will contribute to specific professional practices in the health care context of the } \\
\text { reviewer }\end{array}$ & 2 & 2 & 2 \\
\hline $\begin{array}{l}14 \text { The guidelines will contribute to multiprofessional or other professional practice in the health care } \\
\text { context of the reviewer }\end{array}$ & 2 & 2 & 1 \\
\hline $\begin{array}{l}15 \text { The guidelines will contribute to an overall prevention of visual disturbances within the health care } \\
\text { context of the reviewer }\end{array}$ & 2 & 2 & 1 \\
\hline Standardized domain score of contribution & $67 \%$ & $37 \%$ & $15 \%$ \\
\hline \multicolumn{4}{|l|}{ Comparability $^{\mathrm{a}}$} \\
\hline 16 The guidelines are structured and written in an identical manner & & 2 & \\
\hline 17 The evidence is similarly described, analyzed and synthesized & & 2 & \\
\hline 18 The type and grade of recommendations are identical & & 2 & \\
\hline Standardized domain score of comparability & & $26 \%$ & \\
\hline
\end{tabular}

${ }^{\mathrm{a}}$ Additional domains established by Wimpenny ${ }^{13)}$.

included to assess the potential impact on professional practice in terms of contribution to specific professional practice, contribution to multiprofessional practice and contextual contribution, and Comparability, which was included to evaluate the extent to which the guidelines are comparable in terms of structure and writing, evidence use and recommendations.

Each item was rated on a 4-point Likert scale ranging from 4 (strongly agree) to 1 (strongly disagree), with two midpoints: 3 (agree) and 2 (disagree).

The domain scores were not aggregated into a single average score but, as AGREE recommends, a section for overall assessment was also included that requires the appraiser to make a judgment about the quality of the guidelines.

The appraisal instrument included space for all three sets of guidelines to be assessed simultaneously and to enhance appraisal of comparability. A space for comments was provided next to each item for explanation of similarities or differences and to justify the score.

\section{Procedure}

The first phase, the postal round (Fig. 1), asked 
appraisers to rate the 18 items taking into account research evidence and their opinion/clinical expertise.

Previous research has shown that, without a synthesis of pertinent information, appraisers in the consensus process are more likely to rely entirely on their own particular experiences ${ }^{20)}$. Also, when such information is used during deliberation, the consensus process tends to be more straightforward ${ }^{21)}$ and to reflect the research evidence ${ }^{22}$. In the light of this, the consensus group received relevant evidence on the topic together with the three sets of guidelines, the appraisal instrument and the instruction booklet.

On receipt of the completed appraisal instrument, the frequency of response to each item was calculated. For each item, the pattern of responses for the group was presented alongside each member's response to that item. This presentation allowed appraisers to see the spread of scores and prepare their arguments before the group met face to face (see Fig. 2 for examples).

Following individual appraisal, a meeting was held in October 2009 with appraisers in which they

\section{SCOPE AND PURPOSE \\ [items 1 and 2]}

1. The specific objectives of the guidelines aimed at preventing ocular or visual disturbances associated with exposure are specifically described

UK

\begin{tabular}{|c|c|c|c|c|c|}
\hline Un & $3^{*}$ & & & & \\
\hline Strongly agree & 4 & 3 & 2 & 1 & Strongly disagree \\
\hline French & & $3^{*}$ & & & \\
\hline Strongly agree & 4 & 3 & 2 & 1 & Strongly disagree \\
\hline Spanish & & $3^{*}$ & & & \\
\hline Strongly agree & 4 & 3 & 2 & 1 & Strongly disagree \\
\hline
\end{tabular}

\section{RIGOR OF DEVELOPMENT}

[items 6-9]

7. The criteria for selecting the evidence related to the visual system are clearly defined within the guidelines

UK

Strongly agree

4

3

French

Strongly agree

Spanish

Strongly agree
4

3

12

$1 \quad$ Strongly disagree

CONTRIBUTION

[items 13-15]

14. The guidelines will contribute to multiprofessional or other professional practice in the health care context of the reviewer

UK

$\begin{array}{llllll}\text { Strongly agree } & 4 & 1 & 2^{*} & & \\ \text { French } & 3 & 2 & 1 & \text { Strongly disagree } \\ \text { Strongly agree } & 4 & 3 & 2 & 1 & \text { Strongly disagree } \\ \text { Spanish } & & & 3^{*} & & \\ \text { Strongly agree } & 4 & 3 & 2 & 1 & \text { Strongly disagree }\end{array}$

* Indicates the rating of the individual appraiser for the item

Fig. 2. Examples of spread of agreement for item responses. 
discussed scoring and comments. The items already rated (via the postal round) were discussed in turn, focusing on those that were the source of the most disagreement. There was then an opportunity for each appraiser to privately re-rate the items. It was this rating that was used to determine scores and level of agreement about each item. The group meeting discussion was audio recorded and later transcribed verbatim $^{23,24)}$.

\section{Statistical analyses}

Domain scores were calculated according to AGREE instructions by summing up all the scores of individual items and standardizing the total as a percentage of the maximum possible score for that domain $^{18)}$.

standardized domain score $=$ obtained score - minimum possible score maximum possible score - minimum possible score $\times 100$

Median item scores were also calculated, as they are ordinal categories ${ }^{25}$.

Guidelines are "strongly recommended" for use in practice without provisos or alterations if they receive a high rating ( 3 or 4 ) for the majority of items and most domain scores are above $60 \%$. Guidelines are "recommended" if they receive a high (3 or 4 ) or low rating (1 or 2) for a similar number of items with domain scores between 30 and $60 \%$. Guideline are 'not recommended' if they receive a low rating (1 or 2) for the majority of items and most domain scores are below $30 \%$, which indicates low overall quality and serious shortcoming ${ }^{18)}$.

Inter-rater reliability in the appraisal of each of the three sets of guidelines was evaluated by calculating intraclass correlation coefficients (ICC) and the agreement between each pair of appraisers by the kappa coefficient (two categories were created: 0 , meaning strongly disagree and disagree, and 1, meaning agree and strongly agree). ICC or kappa values above 0.75 , between 0.40 and 0.75 and less than 0.40 were considered to represent good, moderate and poor reliability, respectively ${ }^{26}$.

Differences between scores of each pair of appraisers for each domain (appraisers 1 and 2, appraisers 1 and 3 and appraisers 2 and 3) were also calculated, representing the percentage of these differences by domain. On a 4-point Likert scale, the difference between scores can be $0,1,2$ or 3. Accordingly, four categories were defined: agreement (difference of 0), concordance (difference of 1), variation (difference of 2) and significant variation (difference of 3).

Data were analyzed using the Statistical Package for the Social Sciences (SPSS 17.0) software.

\section{Results}

There are important differences in the scores for all three sets of guidelines; the UK guidelines had the highest scores for most domains (see the median scores by item and the standardized domain scores for each guideline, Table 2). The domain Scope and purpose was scored highest for all three sets of guidelines, while Applicability received the minimum possible score. It should be noted that the items with the lowest evaluations for all three sets of guidelines were in the domains Stakeholder involvement, Rigor of development and Applicability. The domains Stakeholder involvement and Rigor of development had scores under 20\%. The domain Comparability had a standardized domain score of $26 \%$; that is, the appraisers considered that all three sets of guidelines were not developed or presented in a similar way, either in structure or in how they were written, in the use of the evidence relating to the visual system or in the recommendations (items scores were always less than or equal to 2 ).

In the section for overall assessment, the UK guidelines received the highest overall appraisal of the three sets of guidelines; the three appraisers would recommend it with provisos or alterations. The French guidelines were recommended with provisos or alterations by two appraisers, and the other appraiser would not recommend it. However, for the Spanish guidelines, two of the three appraisers indicated they would not recommend it for surveillance of the effects of VDT exposure on workers' visual health, and the other appraiser would only recommend it with provisos or alterations.

The ICCs among the three appraisers were, in decreasing order, 0.84 for the French guidelines, 0.81 for the UK guidelines and 0.53 for the Spanish guidelines (Table 3). That is, the UK and French guidelines had good reliability, while reliability of the Spanish guidelines was moderate. The overall kappa coefficient between each pair of appraisers is slightly higher for appraisers 1 and 3, who were $100 \%$ in agreement in evaluating the Spanish guidelines.

Finally, neither variation nor significant variation was observed for any of the scores. In all cases, either agreement or concordance was reached (Fig. 3). Agreement for the domain Applicability reached 100\% for all three guidelines, and agreement for the domain Scope and purpose was $\mathbf{1 0 0 \%}$ for the UK and French guidelines.

\section{Discussion}

The results of this study indicate that the three guidelines have a low overall quality based on AGREE scoring; moreover, there was consensus from 
Table 3. Reliability between appraisers in the appraisal and comparison of the guidelines: kappa coefficient and intraclass correlation coefficient (ICC)

\begin{tabular}{lccccc}
\hline & \multicolumn{3}{c}{ Kappa coefficient } & & ICC \\
\cline { 2 - 4 } \cline { 5 - 5 } National guidelines & Appraisers 1 and 2 & Appraisers 1 and 3 & Appraisers 2 and 3 & & Appraisers 1, 2 and 3 \\
\hline UK guidelines & 0.40 & 0.33 & 0.82 & 0.67 & 0.81 \\
French guidelines & 0.82 & 1 & - & 0.84 \\
Spanish guidelines $^{\mathrm{a}}$ & - & 0.67 & 0.58 & 0.53 \\
Global & 0.53 & & &
\end{tabular}

${ }^{\mathrm{a}}$ Cannot be calculated for scores of appraiser 2 because all were in category 0 (strongly disagree and disagree).

Agreement

Concordance

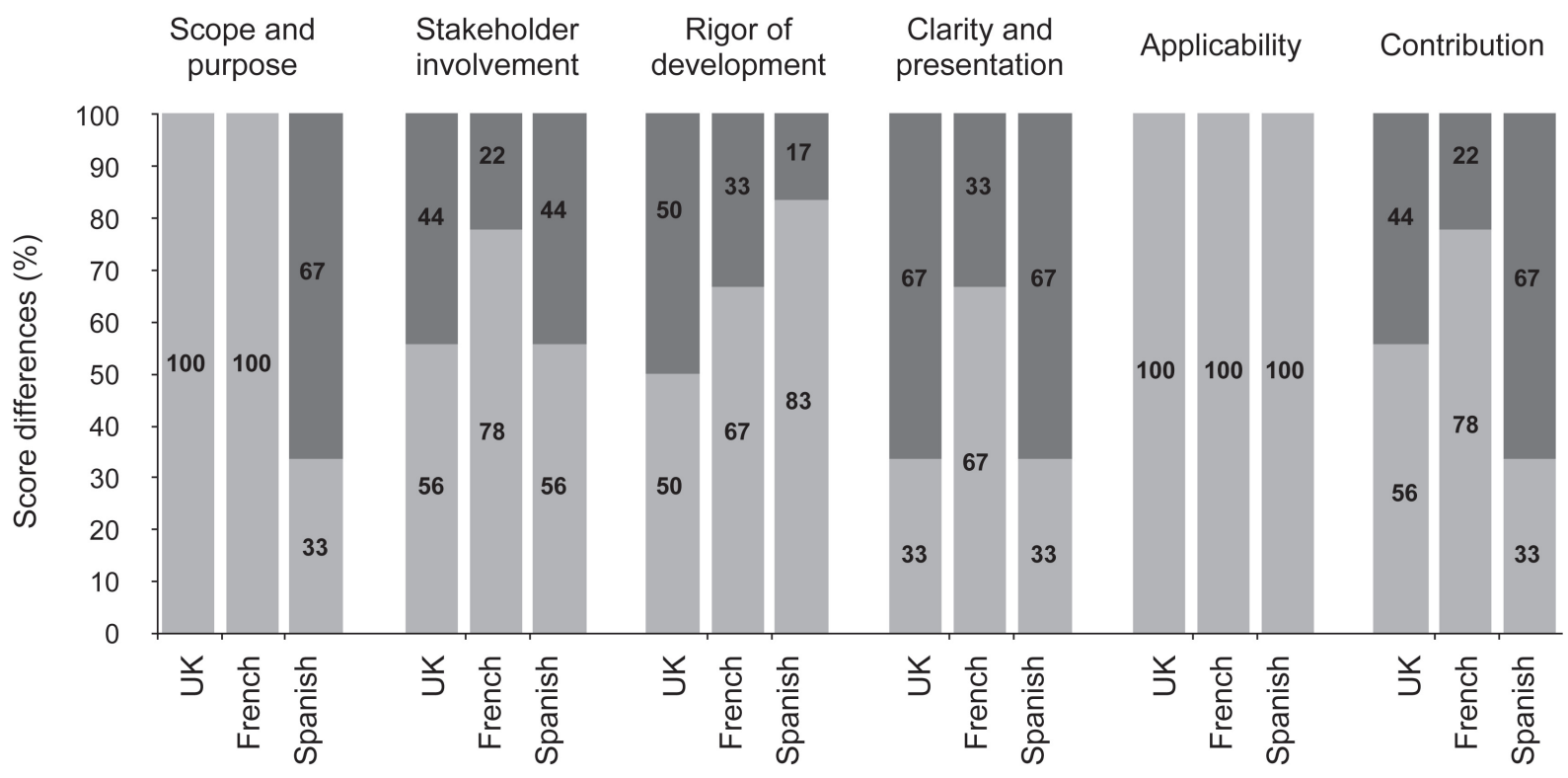

Fig. 3. Percentage of score differences between pairs of appraisers by domain of each of the three sets of guidelines.

appraisers in scores and comments for most items suggesting that the guidelines have serious shortcomings.

The UK guidelines were considered the most specific in setting out the objectives for surveillance of visual disturbances and in defining the visual particularities of the target population. It was rated highly for its contribution to collaboration among professionals and for its well-structured content. Nevertheless, the French guidelines received the highest rating for Clarity and presentation because they incorporated figures to support the text, as well as a glossary of terms.

The poor comparability of the guidelines, however, was surprising considering that they were all derived from the same European directives on workers' protection $^{11)}$. Maybe the limited range of international evidence within the field of occupational health and vision $^{27)}$ could explain this variation, as guideline developers were challenged to develop guidelines with limited evidence. Perhaps occupational health, which is considered to lag behind other medical specialties in terms of failing to embrace evidence-based practice ${ }^{28)}$, needs to enhance its rigor for guideline development.

The low score for some items, such as potential costs of application, previous pilot study and strategy used to search for evidence, does not mean they were not undertaken, but they are not reported in the guidelines. Such lack of transparency increases the number of items with low scores and contributes to a reduction in the overall scores.

Of note is the high level of agreement and concordance among the three appraisers in comparison with the results obtained by other authors ${ }^{29)}$. Such a favorable result may be due to the fact that, unlike other studies $^{13,29)}$, the appraisers here were instructed on the procedure to follow, and moreover, the process ended 
with a face-to-face meeting where they could clarify any doubts that came up during appraisal, which has been shown to improve overall, final agreement ${ }^{12}$.

The kappa coefficient did not show greater agreement between evaluators of the same nationality (appraisers 2 and 3). The highest overall kappa coefficient was found for appraisers 1 and 3, which could be due to their similar professional profiles, related with occupational medicine and nursing, as opposed to appraiser 2, an optometrist with expertise in visual ergonomics. It should be kept in mind that some domains such as Stakeholder involvement or Contribution may be appraised using different criteria depending on the appraiser's clinical or applied experience ${ }^{26)}$. Thus, the variability observed among appraisers in these domains may reflect a combination of measurement error and variation in perspective.

With respect to limitations, the AGREE appraisal instrument focuses more on evaluating the process of guideline development than its contents. This is in line with the general belief that a good development process is associated with high quality contents, which is not always the case $\mathrm{c}^{30,31)}$. Appraising guidelines is not without challenge, as a range of tools/instruments exist that have been used to appraise other occupational health guidelines ${ }^{32}$. It is certainly not clear which one is most appropriate, valid or reliable and which one should be used to appraise which type of guidelines, as significant variations can exist in the structure and process of development. However, the AGREE tool appears to have become more widely accepted as the standard for appraisal of guideline development quality with satisfactory levels of reliability for most of the domains it appraise ${ }^{33}, 34$, and it has been endorsed by the WHO and many national guideline bodies. A variety of adjustments to the tool have been reported ${ }^{33)}$ including modifying its structure, scoring process or addition or omission of domain items, and it has already been used to evaluate the quality of six occupational health guidelines ${ }^{29}$. What appears to be valuable in the use of AGREE is the illumination of aspects related to guideline quality and opportunity to enhance rigor and consistency in future production $^{32}$. Our use of the AGREE instrument is in accordance with specific needs for occupational health surveillance ${ }^{35)}$. Measurement error and variation in the perspective of the appraisers involved and the limited number of appraisers were other disadvantages; however, the guidance for AGREE recommends that each set of guidelines be assessed by at least two and preferably four appraisers to obtain good reliability. Studies comparing reliability for a different number of appraisers have found that the largest increments were obtained when going from two to three appraisers ${ }^{26)}$.

Low item and domain scores for the three sets of guidelines and the agreement between appraisers indicate where improvements are necessary. The recommendations to improve the guidelines were drafted on the basis of the panel's level of agreement at the face-to-face meeting. If appraisers' qualitative responses were considered to agree or there was consensus, the responses were developed into a practical recommendation. Likewise, if they did not reach this level of consensus, they were rejected. First, it would be useful if the guidelines were to specify the material and human resources needed to carry out adequate visual health surveillance. The appraisers went further, declaring that "There is nothing in any of the three national guidelines stating the benefits to employers of complying with the guidelines; nothing explains the cost of the time it takes to perform the assessment and why this will benefit in reducing sickness absence." The appraisers thought it necessary to enhance the scientific evidence on occupational visual health as a basis for the contents of all three sets of guidelines and to establish a specific system for keeping them up to date. The scientific basis for the development of guidelines on occupational health surveillance is the only way to reduce the problems associated with guidance when they are based solely on professional consensus ${ }^{28,}{ }^{36}$ ). The appraisers also emphasized the importance of having visual health specialists like optometrists and ophthalmologists participate in future guideline updates, of consulting the professional sectors most affected and of carrying out pilot studies to establish the needs of exposed workers. It was considered equally important to incorporate reference to education and training of professionals responsible for carrying out surveillance. The guidelines should include recommendations for the collective surveillance of visual health, epidemiological indicators on data collection and evaluation of results to produce information that will allow identification of problems and new needs. Whilst such an appraisal appears to show a considerable number of flaws, this is not unusual for guidelines, particularly in older versions and in areas where evidence is limited or equivocal.

Future studies of VDT use guidelines should examine how they are or have been applied in different European nations. Evaluation of their acceptance by stakeholders such as preventive occupational health services, workers, managers and governments and the need to incorporate needed improvements should be undertaken. As noted in a study comparing diabetes guidelines from various European countries ${ }^{14)}$, one approach would be for representatives from a range of countries to develop a set of European guidelines that could be available in various languages, keeping in mind the need for guidelines that are appropriate 
to the setting where they are to be implemented (for example, see the guideline development process at SIGN) ${ }^{37)}$, including differences in national legislation related to work-related health services and health care providers, among others.

In conclusion, the AGREE tool has been helpful in highlighting inconsistencies in VDT guideline development. The three sets of guidelines evaluated do not appear to be adequate for guiding assessment of visual health in VDT workers. Adhering to the structure required by AGREE could be valuable in producing more reliable and valid VDT guidance across all European countries, particularly when they are based on central directives and a limited range of available evidence. The results suggest the need for responsible institutions to review and update these sets of guidelines and to establish further evidence-based recommendations that are useful and applicable for visual health surveillance. There is also the potential to create European guidelines that could make better use of resources for development, be more consistent and contribute to more appropriate interventions for workers using VDTs across Europe.

Acknowledgments: This study was supported by the National Institute for Occupational Safety and Health at Work of the Spanish Work and Immigration Ministry (INSHT). Project reference: 606/UAL/ PVDVIS.

The authors would like to thank the three appraisers who agreed to take part in this study.

\section{References}

1) Parent-Thirion A, Fernández Macías E, Hurley J, Vermeylen G. Fourth European Working Conditions Survey. Luxembourg: Office for Official Publications of the European Communities. [Online]. 2007 [cited 2011 May 15]. Available from: URL: http://www. eurofound.europa.eu/pubdocs/2006/98/en/2/ef0698en. pdf

2) Paoli P. First European Survey on the work environment 1991-1992. Luxembourg: Office for Official Publications of the European Communities. [Online]. 1992 [cited 2011 May 15]. Available from: URL: http://www.eurofound.europa.eu/pubdocs/1992/11/ en/1/ef9211en.pdf

3) Woods V. Musculoskeletal disorders and visual strain in intensive data processing workers. Occup Med (Lond) 2005; 55: 121-7.

4) Tamez González S, Ortiz-Hernandez L, MartinezAlcantara S, Mendez-Ramirez I. Risks and health problems caused by the use of video terminals. Salud Publica Mex 2003; 45: 171-80 (in Spanish).

5) Dain SJ, McCarthy AK, Chan-Ling T. Symptoms in VDU operators. Am J Optom Physiol Opt 1988; 65: 162-7.

6) Sheedy JE. Vision problems at video display termi- nals: a survey of optometrists. J Am Optom Assoc 1992; 63: 687-92.

7) Thomson WD. Eye problems and visual display terminals - the facts and the fallacies. Ophthalmic Physiol Opt 1998; 18: 111-9.

8) Blehm C, Vishnu S, Khattak A, Mitra S, Yee RW. Computer vision syndrome: a review. Surv Ophthalmol 2005; 50: 253-62.

9) Mocci F, Serra A, Corrias GA. Psychological factors and visual fatigue in working with video display terminals. Occup Environ Med 2001; 58: 267-71.

10) Piccoli B. A critical appraisal of current knowledge and future directions of ergophthalmology: consensus document of the $\mathrm{ICOH}$ Committee on "Work and Vision". Ergonomics 2003; 46: 384-406.

11) Council Directive 90/270/EEC of 29 May 1990 on the minimum safety and health requirements for work with display screen equipment (fifth individual Directive within the meaning of Article 16 (1) of Directive 89/391/EEC) Official Journal L 156, 21/06/1990 P. 0014-0018

12) Nast A, Spuls Ph, Ormerod AD, et al. A critical appraisal of evidence-based guidelines for the treatment of psoriasis vulgaris: "AGREE-ing" on a common base for European evidence-based psoriasis treatment guidelines. J Eur Acad Dermatol Venereol 2009; 23: 782-7.

13) Wimpenny P, van Zelm R. Appraising and comparing pressure ulcer guidelines. Worldviews Evid Based Nurs 2007; 4: 40-50.

14) Stone MA, Wilkinson JC, Charpentier G, et al. Evaluation and comparison of guidelines for the management of people with type 2 diabetes from eight European countries. Diabetes Res Clin Pract 2010; 87: 252-60.

15) Health and Safety Executive. Work with display screen equipment: Health and Safety (Display Screen Equipment) Regulations 1992 as amended by the Health and Safety (Miscellaneous Amendments) Regulations 2002. Guidance on Regulations. $2^{\mathrm{a}}$ ed. London: HSE Books. [Online]. 2003 [cited 2011 May 15]. Available from: URL: http://www.hse.gov. uk/pubns/priced/126.pdf

16) Cail F. Écrans de visualisation. Santé et ergonomie. Paris: L'Institut National de Recherche et de Sécurité (INRS). [Online]. 2005 [cited 2011 May 15]. Available from: URL: http://www.inrs.fr/inrspub/inrs01.nsf/intranetobjectaccesparreference/ ED\%-20924/\$file-/ed924.pdf

17) Comisión de Salud Pública. Consejo Interterritorial del Sistema Nacional de Salud. Protocolos de Vigilancia Sanitaria Específica: Pantallas de Visualización de Datos. Madrid: Ministerio de Sanidad y Consumo. [Online]. 1999 [cited 2011 May 15]. Available from: URL: http://www.msps. es/ciudadanos/saludAmbLaboral/-docs/datos.pdf

18) The AGREE Collaboration. Appraisal of Guidelines for Research \& Evaluation (AGREE) Instrument. [Online]. 2001 [cited 2011 May 15]. Available from: URL: http://www.agreecollaboration.org/ 
19) Seguí MM, Ronda E, López A, Juan PV, Tascón E, Martínez FM. Health Surveillance Guide of workers using video display terminals: evaluation from a visual health perspective. Rev Esp Salud Publica 2008; 82: 691-701 (in Spanish).

20) Fink A, Kosecoff J, Chassin M, Brook R. Consensus methods: characteristics and guidelines for use. Am J Public Health 1984; 74: 979-83.

21) Jacoby I. Evidence and consensus. JAMA 1988; 259: 3039.

22) Murphy MK, Black NA, Lamping DL, et al. Consensus development methods, and their use in clinical guideline development. Health Technol Assess 1998; 2: i-iv, 1-88.

23) Raine R, Sanderson C, Hutchings A, Carter S, Larkin K, Black N. An experimental study of determinants of group judgments in clinical guideline development. Lancet 2004; 364: 429-37.

24) Rycroft-Malone J. Formal consensus: the development of a national clinical guideline. Qual Health Care 2001; 10: 238-44.

25) Sánchez Pedraza R, Jaramillo González LE. Methodology of Qualification and Summary of the Opinions in Formal Consensus. Rev Colomb Psiquiatr 2009; 38: 777-86 (in Spanish).

26) MacDermid JC, Brooks D, Solway S, Switzer McIntyre S, Brosseau L, Graham ID. Reliability and validity of the AGREE instrument used by physical therapists in assessment of clinical practice guidelines. BMC Health Serv Res 2005; 5: 18.

27) Melrose AS, Graveling RA, Cowie H, Ritchie P, Hutchison P, Mulholland RM. Better Display Screen Equipment (DSE) work-related ill health data. London: HSE Books. [Online]. 2007 [cited 2011 May 15]. Available from: URL: http://www.hse.gov. uk/research/rrpdf/rr561.pdf

28) Birrell L, Beach J. Developing evidence-based guidelines in occupational health. Occup Med (Lond) 2001; 51: 73-4.

29) Hulshof C, Hoenen J. Evidence-based practice guidelines in OHS: are they agree-able? Ind Health 2007; 45: 26-31.

30) Vlayen J, Aertgeerts B, Hannes K, Sermeus W, Ramaekers D. A systematic review of appraisal tools for clinical practice guidelines: multiple similarities and one common deficit. Int $\mathrm{J}$ Qual Health Care 2005; 17: 235-42.

31) Cates JR, Young DN, Bowerman DS, Porter RC. An independent AGREE evaluation of the Occupational Medicine Practice Guidelines. Spine J 2006; 6: 72-7.

32) Manchikanti L, Singh V, Helm S 2nd, Trescot AM, Hirsch JA. A critical appraisal of 2007 American College of Occupational and Environmental Medicine (ACOEM) Practice Guidelines for Interventional Pain Management: an independent review utilizing AGREE, AMA, IOM, and other criteria. Pain Physician 2008; 11: 291-310.

33) Scott NA, Moga C, Harstall C. Making the AGREE tool more user-friendly: the feasibility of a user guide based on Boolean operators. Journal of Evaluation in Clinical Practice 2009; 15: 1061-73.

34) The AGREE Collaboration. Development and validation of an international appraisal instrument for assessing the quality of clinical practice guidelines: the AGREE project. Qual Saf Health Care 2003; 12: $18-23$.

35) Maqueda J, Buendía MJ, Gallego I, Muñoz C, Roel JM. Estudio de evaluación del Protocolo de Vigilancia Sanitaria Específica del Asma Laboral mediante el instrumento AGREE. Medicina y Seguridad del Trabajo 2006; 52: 13-21 (in Spanish).

36) Waddell G, Burton AK. Occupational health guidelines for the management of low back pain at work: evidence review. Occup Med (Lond) 2001; 51: 124-35.

37) Scottish Intercollegiate Guidelines Network. SIGN 50: a guideline developer's handbook. Edinburgh: SIGN. [Online]. 2008 [cited 2011 May 15]. Available from: URL: http://www.sign.ac.uk/pdf/ sign50.pdf 